\title{
Incarcerated inguinal hernia in infancy associated with testicular infarction: Case report and review of the literature
}

\author{
Fahad Alyami, MD; Thomas Whelan, MD, FRCSC \\ Department of Urology, Saint John Regional Hospital, Dalhousie University, Saint John, NB
}

Cite as: Can Urol Assoc J 2013;7(5-6):e367-9. http://dx.doi.org/10.5489/cuaj.1220 Published online May 13, 2013.

\section{Abstract}

One of the most common urgent urologic problems seen in young patients in the emergency department is the acute scrotum. Testicular infarction from an incarcerated inguinal hernia is an unusual presentation and often not considered in the initial evaluation. We present an interesting case of a 28-day-old boy who presented with an acute scrotum and was found to have a testicular infarction and an incarcerated inguinal hernia. The management of similar cases in young males may vary depending on which surgical service is consulted initially and a scrotal ultrasound should be done without any delay.

\section{Case report}

A 28-day-old boy with right scrotal swelling was brought in to the emergency department (ED) by his parents. His mother noticed he was irritable and crying on the morning of the presentation. He was breastfeeding with no vomiting, diarrhea or other symptoms. He saw his family physician at noon and had a normal exam. His mother later noticed right-sided scrotal swelling while changing his diaper and he started to be more irritable. There was no history of trauma. His medical history revealed an uncomplicated delivery and normal neonatal physical exam. His family history was unremarkable.

He was seen in the ED by the emergency physician within 3 hours of the scrotal swelling. Urology was consulted to rule out testicular torsion.

He was comfortable and not in distress. His vital signs were within the normal ranges and he was well-hydrated. Chest exam was normal. The abdomen was soft and nontender. The right scrotum was swollen and tender. There was no change in the scrotal skin colour. The left testicle was easy to feel and felt normal in the scrotum. It was dif- ficult to palpate the right testicle as there was palpable right swelling suggestive of inguinoscrotal hernia. Scrotal transillumination was negative. He was uncircumcised with a normal phimotic foreskin. The cremasteric reflex was absent on the right side and present on the left side. The rest of the examination was unremarkable.

The scrotal ultrasound showed evidence of bowel contents in the right scrotum, no blood flow to the right testicle and a reactive hydrocele. There was normal blood flow to the left testicle (Fig. 1). The patient was immediately taken to the operating room. The general surgery team was consulted and reduction of the hernia was done under anesthetic before the scrotal exploration. We used bilateral transverse scrotal incisions for exposure because of surgeon preference. Intraoperative examination revealed an ischemic looking right testicle with torsion of the spermatic cord (Fig. 2). The right testicle was detorted and wrapped in warm gauze. We proceeded with performing an orchidopexy on the left testicle. The left testicle was normal. After 30 minutes we inspected the right testicle again and it was still black in colour. The tunica albuginea was incised and it did not bleed. As a result, it was felt that the testicle was non-viable and a right orchiectomy was performed. The general surgery team decided not to repair the hernia at this point secondary to the edema and swelling and preferred to do it on elective basis.

\section{Discussion}

One of the most common urgent urologic problems seen in the ED is the acute scrotum. On the forefront of each clinician's mind is the possibility of testicular torsion. The diagnosis of testicular torsion, however, is not always straightforward because of other processes, such as torsion of a testicular or epididymal appendage, epididymitis, tumour, incarcerated hernia or trauma. The history and physical examination, timing of presentation relative to the onset of the symptoms, and the age of the child are often the key 


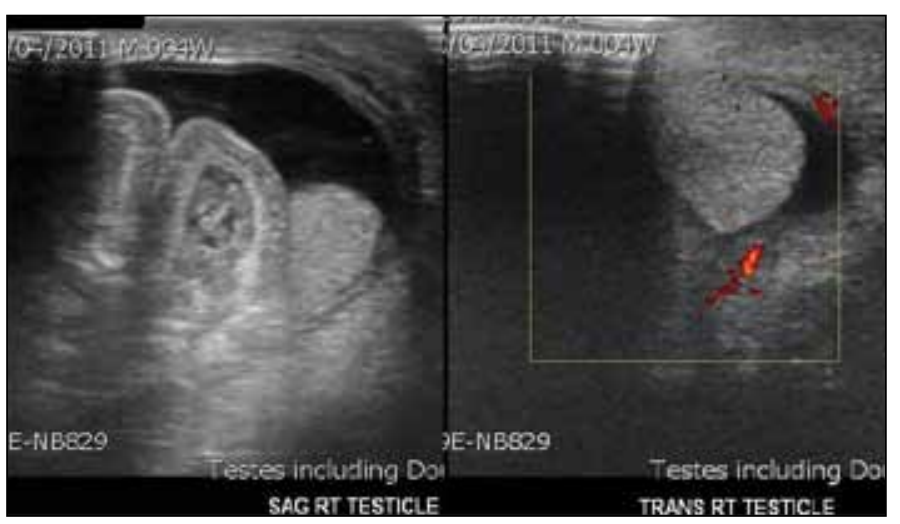

Fig. 1. Ultrasound of the scrotum with Doppler study showing no blood flow to the right testicle and right inguinal scrotal hernia.

in making the correct diagnosis. The only condition that requires emergent surgery is testicular torsion. Testicular torsion presents in a bimodal age presentation, with extravaginal torsion occurring in the perinatal period and intravaginal torsion peaking in puberty, although the latter can be seen at any age. ${ }^{1-3}$ It is unusual to see testicular torsion in the first few months of life, but it is still possible and it should be on the differential diagnosis list. At this age the diagnosis is difficult, as physical findings may be subtle. Patients with postnatal torsion have more favourable salvage rates of $30 \%$ to $40 \%$ and should undergo emergent surgical intervention. ${ }^{4}$ It is controversial whether a contralateral orchidopexy is needed as it is an extravaginal process. One must weigh the risk of injuring a healthy, uninvolved contralateral testicle when proceeding with a prophylactic maneuver to prevent potential future torsion. It remains unknown whether individuals with unilateral neonatal testicular torsion are at increased risk for torsion of the remaining solitary testicle. ${ }^{5,6}$

However, asynchronous torsion is not as rare an event as previously reported and it may pose a diagnostic challenge. The risk of asynchronous contralateral testicular torsion in different series is between $2 \%{ }^{7}$ and $33 \% .^{8}$ If the surgeon decides not to do contralateral orchidopexy, it is important to counsel the parents to watch for any signs suggestive of contralateral torsion. This may place a heavy burden on already traumatized parents.

Inguinal hernias are common scrotal masses in young patients and are almost always indirect hernias resulting from a patent processus vaginalis. The concern in the young, preverbal population is that caregivers may not recognize the signs and symptoms of incarceration. Delay in seeking medical attention may lead to incarceration with subsequent strangulation of the hernia. The condition may also lead to bowel obstruction with development of ischemia, further leading to gangrene and septicemia. Reduction of the hernia should be done early, not only to preserve the bowel, but also to avoid pressure on the ipsilateral spermatic cord and prevent testicular ischemia. ${ }^{9}$

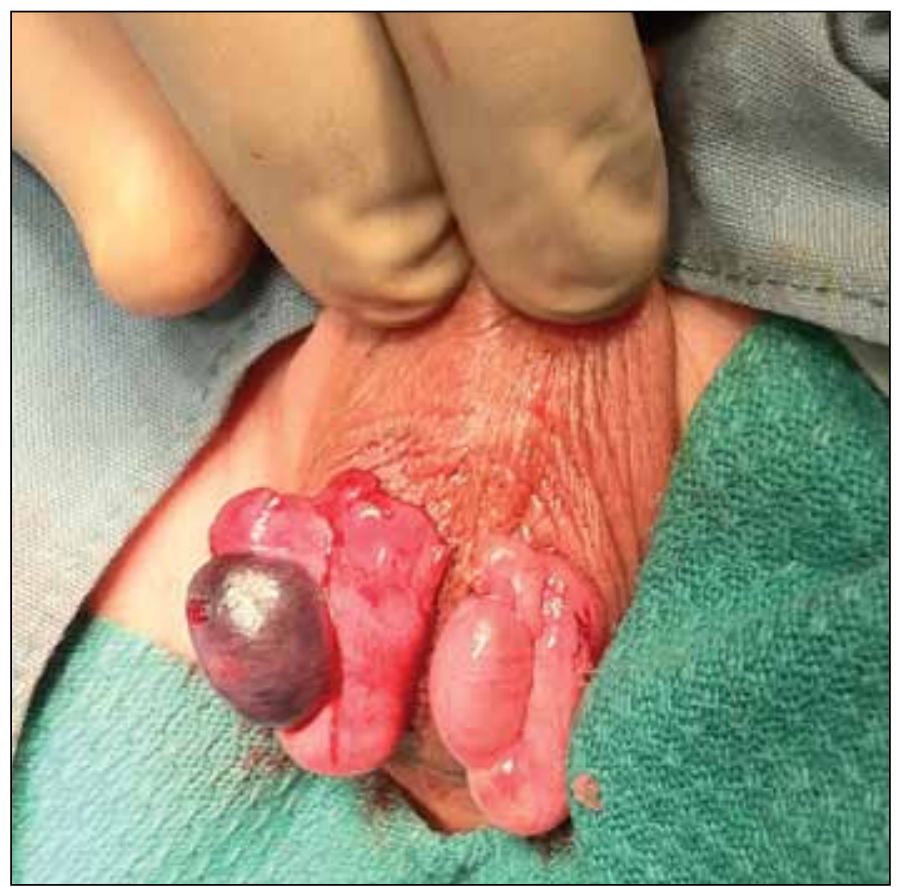

Fig. 2. Intraoperative picture showing both testicles.

Five cases are reported of patients who presented with incarcerated inguinal hernia and testicular infarction. ${ }^{10-14}$ The association between the incarcerated inguinal hernia and testicular infarction can be coincidental or can be related. Although actual twisting of vessels is the most common reason, other mechanisms, such as vessel compression, may result in ischemia and infarction. History and physical exam are important tools to diagnose torsion and incarcerated inguinal hernia when they present separately. Ultrasound with Doppler is particularly valuable to confirm the diagnosis.

\section{Conclusion}

The management of the acute scrotum in a neonatal male may vary depending on what surgical service is consulted initially. In our case, the urology service was asked to see the boy first and a Doppler ultrasound was organized, as well as a surgical consult for the hernia. However, if the primary consultation was for the surgical team regarding the hernia and it was easily reduced, the torsion would likely not have been diagnosed. In this case despite the fact that the torsion was not detorted in the time to save the testicle, it still emphasizes the importance of considering both diagnoses in the neonatal boy. The question is: does every male child who presents with an incarcerated inguinal hernia need a scrotal ultrasound with Doppler? We suggest performing a scrotal ultrasound if done without delay on children presenting with scrotal swelling suggestive of incarcerated inguinal hernia to rule out testicular infarction until this issue is addressed by further studies. 
Competing interests: None declared.

This paper has been peer-reviewed.

\section{References}

1. Sparks J. Torsion of the testis. Clin Pediatr (Phila) 1972;11:484-6. http://dx.doi. org/10.1177/000992287201100817

2. Al-Salem AH. Intra-uterine testicular torsion: early diagnosis and treatment. BJU Int 1999;83:1023-5. http://dx.doi.org/10.1046/i.1464-410x.1999.00099.x

3. Arena F, Nicotina PA, Scalfari $G$, et al. A case of bilateral prenatal testicular torsion: Ultrasonographic features, histopathological findings and management. J Pediatr Urol 2005;1:369-72. http://dx.doi. org/10.1016/i.jpurol.2005.03.001

4. Sorensen MD, Galansky SH, Striegl AM, et al. Perinatal extravaginal torsion of the testis in the first month of life is a salvageable event. Urology 2003;62:132. http://dx.doi.org/10.1016/S00904295(03) 00402-3

5. Harris BH, Webb HW, Wilkinson AH Jr, et al. Protection of the solitary testis. J Pediatr Surg 1982;17:950. http://dx.doi.org/10.1016/S0022-3468(82)80473-9
6. Bellinger MF. The blind-ending vas: the fate of the contralateral testis. J Urol 1985;133:644.

7. Djahangirian 0 , Ouimet $A$, Saint-Vil $D$. Timing and surgical management of neonatal testicular torsions. J Pediatr Surg 2010;45:1012-5. http://dx.doi.org/10.1016/i.jpedsurg.2010.02.032

8. Baglaj $M$, Carachi R. Neonatal bilateral testicular torsion: a plea for emergency exploration. J Urol 2007;177:2296-9. htrp://dx.doi.org/10.1016/i.juro.2007.02.005

9. Mesrobian HG, Balcom AH, Durkee CT. Urologic problems of the neonate. Pediatr Clin North Am 2004:51:1051-62. http://dx.doi.org/10.1016/i.pcl.2004.03.016

10. Waseem $M$, Pinkert $H$, Devas $G$. Testicular infarction becoming apparent after hernia reduction. J Emerg Med 2010;38:460-2. http://dx.doi.org/10.1016/i.jemermed.2008.01.032

11. Gamble WG, Keller GA. Testicular infarction associated with incarcerated inguinal hernia. Minn Med 1987;70:529-32.

12. Onuora VC, Chiedozi LC. Testicular infarction complicating strangulated inguinal herniae in Nigerian children. Trop Geogr Med 1993;45:129-30.

13. McGurk MN. Testicular infarction with incarcerated inguinal hernia in infants. N Z Med J 1978;88:14.

14. Hanna BK. Incarcerated inguinal hernia in infancy associated with testicular infarction. J Ir Med Assoc 1972;65:372-3

Correspondence: Dr. Fahad Alyami, Department of Urology, Dalhousie University, QEll Health Sciences Centre, VG Site, Room 294, 5 Victoria, 1276 South Park St., Halifax, NS B3H 2Y9; falyami@dal.co 